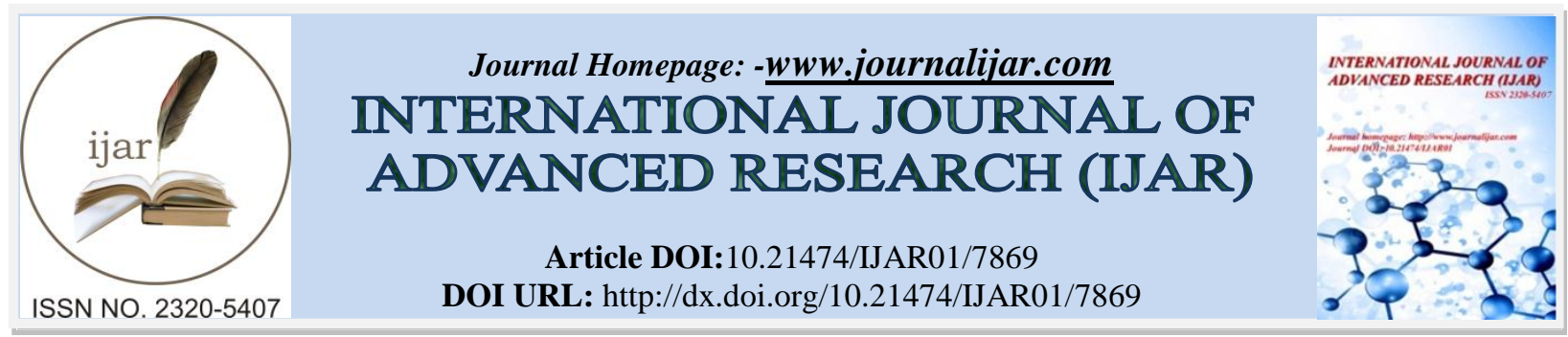

RESEARCH ARTICLE

\title{
KHAT CHEWING PRACTICE ITS PERCEIVED HEALTH EFFECT AND ASSOCIATED PROBLEMS WITH KHAT CHEWING AMONG COMMUNITIES OF CHIRO TOWN.
}

\author{
Getachew Gashaw Dagnew \\ Department of Biology College of Natural and Computational Science, Oda Bultum University, Chiro, Ethiopia. \\ P.O. Box 226.
}

\section{Manuscript Info}

Manuscript History

Received: 9 August 2018

Final Accepted: 11 September 2018

Published: October 2018

\section{Keywords:-}

Khat; khat chewing; perceived health Effect.

\section{Abstract}

Khat is found in the evergreen tree or large shrub consists of whole rash leaves and buds of a plant known as Catha edulis. It is an indigenous tree to Ethiopia, Kenya, and more than 20 different compounds are fund in khat. Khat chewing practice renders certain influence on physical and psychological well being of the community and it can cause more serious adverse psychiatric, cariodiovascular, dental and gastrointestinal effect. The recent sharp increase khat consumption may not only affect the health of individuals but could also have serious socio - economic consequences. This study was conducted to assess prevalence of khat chewing practice; it perceived health effect among chiro town. Community based cross- section study was determined by using single population proportion formula and 20 households were selected by systematic sampling method and in the selected by lottery among members of household aged 15 years old and above. Data were collected by manse of questioner analysis was carried out using SPSS version 20. For the qualitative part 264 individuals were purposely selected and sample size for this method was determined through participant.

Results: The khat chewing is most commonly practiced among male gender (72\%) compared to female (28\%). Muslim were more likely to chew khat (38\%) compared to orthodox Christians and other. Respondent who had family member without a chewer. Among the entire respondent $94.7 \%$ agree on chat chewing practice had perceived health effect and 5.3\% of the respondent Dis agree.

Conclusions: The prevalence of khat chewing practice was $62 \%$ with high proportion of the khat chew found in the urban setting. Sex, religion, residence, family chewing habit and perceived health effect were significantly associated factors with khat chewing practice. In this study $94.7 \%$ of the respondents perceived that khat chewing practice had harmful effect on health and the perceived health effect reported were slapping disorder, hallucination, hypertension, loss of appetite, depression and gastrointestinal adverse effect like gastritis.

Copy Right, IJAR, 2018,. All rights reserved. 


\section{Introduction:-}

Khat is one of a stimulant drugs got from a tree called Catha edulis people have consumed khat for its stimulating effect (Cox and Ramped 2003,456) it has slightly narcotic properties and its leaves are usually chewed. The main phychiatr ingredients are cathine and cothinone (The dependent producing constituent of khat leaves) chemical that are similar to amphetamine (NIDA.2010) khat leaves are chewed for their euphoric effect to guard off tiredness and with the assumption that chewing chat facilitates learning. World health organization (1980) classified it as a drug of a drug of abuse that can produce mild to moderate psychological effect (less than tobacco or alcohol).

According to the world health organization substance abuse is defined as the use of other substance for non medical purposes with the aim of producing a mind altering effect in the use (WHO).According to this organization it involves the use of substance such as cannabis (Marijuana) khat misuse of legal drug or use of a drug for purposes other than that for which they are intended (WHO, 2006; Rehm and Eschmann, 2002).

According to united nation office of drug and crime (UNODC) (2008) 205 Million people are involved in substance abuse World wide of these 25 Million people aged 15-64 are estimated to problem of drug users Many of Who are unable to stop without treatment the regional of Africa in the report is between 25.7 Million and 80.8 Million among the same aged group (world Drug Report 2011) Report of world Health organization(2006) showed that while 17 to $42 \%$ of south's sub Sahara Africa are involving in chronic excessive drinking of alcohol those involved in abusing drug such as canabis and others like khat are 7 to 38\%.chronic khat use associated with adverse health effect such as hypertension heart rhythmdisorder,insomnia liver toxicity,oral cancer hypertension spermatorrhoea and hemorrhoid ,loss of appetite and gastrointestinal effect medical problem associated with khat in toxication including psychophysical function and schizophreniform psychoses some other khat chewers also experience anxiety, tension restlessness, hypongoic,hallucination hypomania and aggressive behavior or psychosis.

Khat chewing is neither a habit confined to any specific socio economic group nor gender specific .It is common habit among all segment of the Ethiopian. Population studies show that khat consumptions is widely experienced by both the young in school and out of school and the old though the young are the most affected group (Ehen and Stanley, 2004) It is widely understood that the consumption of khat creates remarkable problem for today youth which is no limited to individual user. Rather its adverse negatively consequence is believed to be challenging to a family, the community as a whole ,economy and political area of a given nation (Ihezue,1999).many countries including Ethiopian reorganization that substance abuse by young is a serious health economic and social problems. In addition khat chewers spend consideration time on this habit time wasting effect the stud's time of student.

\section{Objective:-}

The aim of this study was to determine the prevalence and health effect of khat chewing and identify the health consequence of abusing khat among communities of chiro town.

\section{Materials and Methods:-}

Description of the Study Area

This research was conducted in west Hararghe zone chiro town. It is geographically located between $34^{\circ} \mathrm{c} 18^{\prime}$ ' $43^{\prime \prime}$ to $43^{\circ} 0$ to $4^{\prime \prime} \mathrm{E}$ latitude and $10^{\circ} 09^{\prime} 24$ ' to $30^{\circ} \mathrm{c} \mathrm{s} 18^{\prime}, 43^{\prime}$ ' longitudes N. It has altitude and longitude on altitude of $1826 \mathrm{~m}$ above sea level it is the administrative center of west harerghae zone (Source west harerghae zone district agricultural office, 2010. 


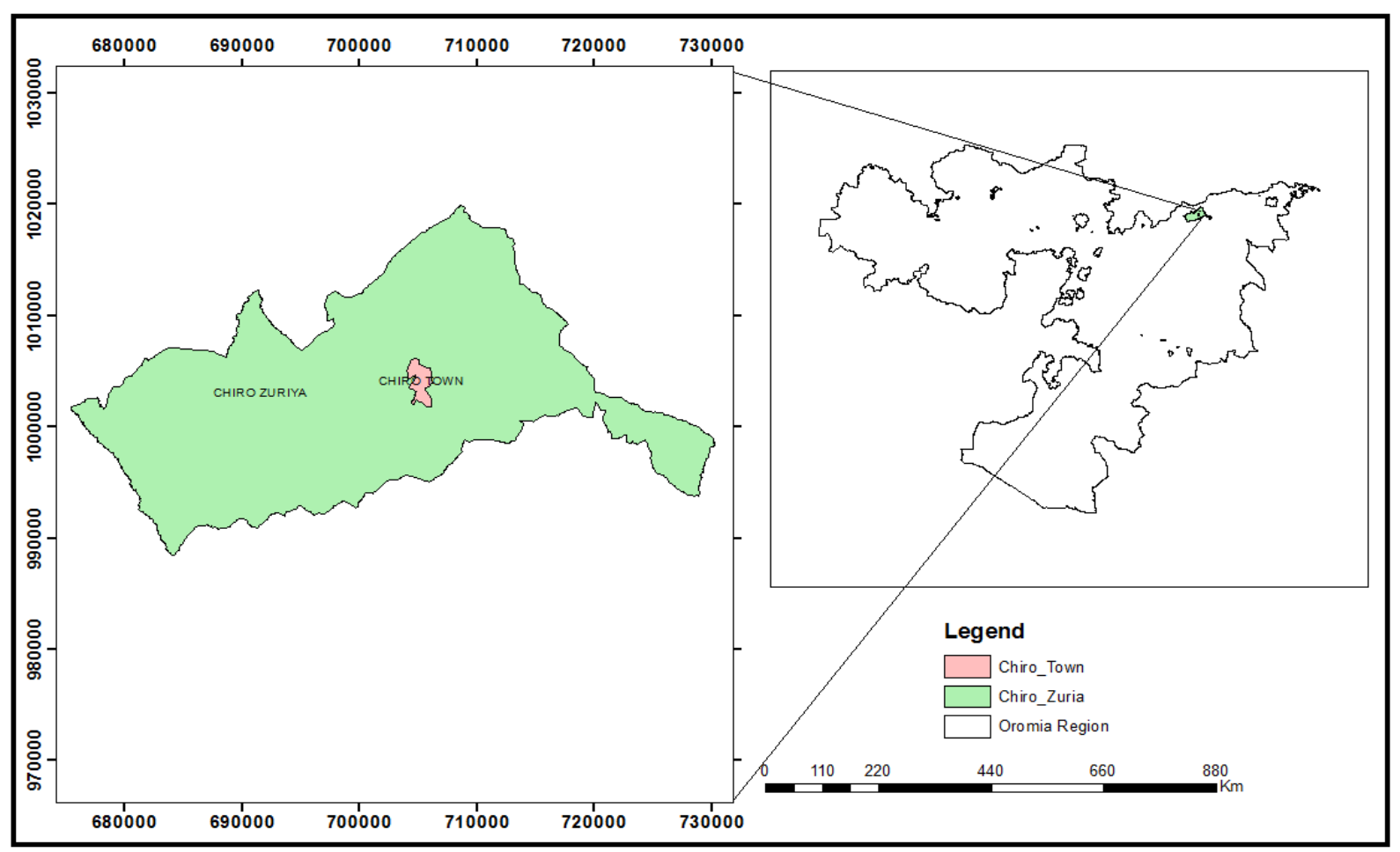

\section{Research Design}

Figure 1:-Map of study area

A quantitative research method was used in the study. Quantitative research focuses on gathering numerical data and generalizing it across groups of people or to explain a particular phenomenon (Creswell, 2003). As suggested by this author, quantitative method is the preferred one if the goal of the study is to establish the relationship between one thing (dependent variable) and another thing (independent variable) in a population. Thus this was preferred to determine the relationship between dependent variable (in this khat chewing) and independent variables which include demographic ( such as age, gender, place of origin, academic status, level of education) and socio-economic variable ( such as peer influence, accessibility, family influence and personal factors) among chiro town.

The study design was cross-sectional and the data was collected in April, July, 2018. The reason why this study is cross -sectional is that is major objective is identifying the current determining factors and the risks associated with khat chewing behavior among students rather than its change over the period of time.

\section{Sampling Technique}

\section{Sample size Determination}

Sampling size for the study was determined based on the formula size determination suggested by Kothari (2004). The level of significance is taken as $95 \%(\mathrm{Z}=1.96)$, margin of error $5 \%(\mathrm{e}=0.05)$. The sample size was calculated using the following standardized formula.

$\mathbf{n}=$

$$
\frac{Z^{2}}{4 e^{2}+Z^{2} / N}
$$

Where $\mathrm{n}=$ required sample size, $\mathrm{N}=$ population size-critical value $95 \%$ confidence level assumption (1.96) and emargin of error between the sample and population or the precision $(0.05)$.

Thus the sample size is calculated as $n=1.96^{2} /\left(4 * 0.05^{2}\right)+1.96^{2} / 54,307=3.84 / 0.010070709=264$

Therefore, according to this formula the determined sample size is 264 of the chiro town. 


\section{Sampling Procedures}

Chiro town was chosen for study on the basis that khat plant is highly cultivated and easily accessible to the consumers. This also has the implication on both cost and time. Since khat is highly supplied and easily accessible to the users in the town the user are able to get it with low cost and whenever needed. This again leads to the increment of the prevalence of khat chewing in the study area.

\section{The data collection instrument and Procedures}

The proposed study was employed survey research design, it used questionnaires was developed by reviewing the relative literature and previously used instrument which was adopted and modified from WHO- students drug use survey questionnaire (WHO,2002). The question was dividing into three sections socio-demographic back grounds; khat chewing habit and associated problems with khat chewing. The questionnaires were distributed and collected by class student's leaders under supervision of research assistant hence the primary data was collected through this structures self- administered questionnaire from 264 respondents out of the total population of 54.307.

\section{Data Analysis}

After the collection of data the researcher checked the completed questionnaires; responses were coded, cleaned and entered to computer using IBM statistics SPSS version 20 statistical program for analysis. Data collectors through questionnaire were analyzed using the logistic regression model. According to IBM Manual, logistic regression is used to predict the presence or absence of a characteristic or outcome based on values of a set of predictor variable. Thus it is said to be well suited for assessing and two or more independent or predictor variable son a dichotomous repose variable, current khat chewing status which is categorized in to the population participating in the study.

\section{Reliability and validity}

Data collection tools were prepared in English which is the medium of instruction in Ethiopian higher Education institutions. During the data collection process, supervision was conducted strictly and frequently. After the collection of data completeness of the required type of data was checked for accuracy and consistency before the entry of data to the SPSS.

\section{Population of the study area}

The current (2017) total population is 54,307 from these 28,971 men and 25,336 women. The dominant ethnic group are Oromo people but the total population are a mixture of the different ethnic group (Source Ethiopian national census 2017) and Harerghae zone disteininct statically office (2017) the majority of the population in habitants said they are Muslim's.

\section{Result and Discussion:-}

In this study, a total of 264 peoples were participated and all of the participants completed the questionnaires making the respondent rate $100 \%$.

\section{Socio- demographic characteristics of Respondents}

The socio demographic variable used in the study was family structure of the respondent. Respondents are asked about their parent existence, hence concerning parental presence of respondent were headed by single family. Both families headed and the remaining grows up with other relatives.

Among the study participant, the majority 190 (72\%) were male, all of the respondent were aged 18-26 years and the mean age of the respondents were 21.87 years (SD+1.875 years). Regarding place of origin most of the people $164(62 \%)$ were from urban areas and the remaining $100(38 \%)$ were from rural areas. The result was shown in table of socio- demographic characteristics of the respondent.

Table 1:-Description of socio- demographic characteristics of chiro town $(n=264)$

\begin{tabular}{|l|l|l|}
\hline Age & Number & Percent \\
\hline $18-20$ & 68 & 25.7 \\
\hline $30-40$ & 145 & 55 \\
\hline $41-60$ & 51 & 19 \\
\hline Total & $\mathbf{2 6 4}$ & $\mathbf{1 0 0}$ \\
\hline Gender & & \\
\hline
\end{tabular}




\begin{tabular}{|l|l|l|}
\hline Male & 190 & 72 \\
\hline Female & 74 & 28 \\
\hline Total & $\mathbf{2 6 4}$ & $\mathbf{1 0 0}$ \\
\hline Place of Origin & & \\
\hline Urban & 164 & 62 \\
\hline Rural & 100 & 38 \\
\hline Total & $\mathbf{2 6 4}$ & $\mathbf{1 0 0}$ \\
\hline Family Structure & & \\
\hline Both Parent & 99 & 37.7 \\
\hline Single headed & 128 & 48.5 \\
\hline Other relative & 37 & 14 \\
\hline Total & $\mathbf{2 6 4}$ & $\mathbf{1 0 0}$ \\
\hline Religion & & \\
\hline Muslim & 100 & 38 \\
\hline Orthodox & 74 & 28 \\
\hline Other & 90 & 34 \\
\hline Total & $\mathbf{2 6 4}$ & $\mathbf{1 0 0}$ \\
\hline
\end{tabular}

Chat Chewing Frequency/prevalence and Starting Time of Chat Chewing

The frequency/prevalence of chat chewing among the study population was shown in table 2 . Out of the total respondants, $232(87.9 \%)$ of the respondants replied that they were chewing chat every day and $18(6.8 \%)$ of them also replied that they were chewing chat from 3-4 days per week. Few respondants said that they were chewing chat from 1-2 days per week because of financial problem. The majority of the respondants were started chewing chat at elementary school (64.8\%); at University (14\%) and at Secondary School (13.3\%). Few respondants were also replied that, they were started chewing chat at preparatory school level. The common reason for chewing chat al elementary school level was due to family chewing habit, academic purpose and peer pressure. The prevalence of khat chewing has been higher in Ethiopia. In the same manner this study found that out of the targeted sample $(n=264)$, the current prevalence of khat chewing were higher counting $87.7 \%$ among chiro town. This prevalence was higher than that of a study conducted in northern part of Ethiopia, among Axum university which was $28.7 \%$ prevalence for life time and for current chewers ( Measho et al.,2012), and at Mekelle university which was 14.8\% ( kidan A.,2011) . As the finding of the study indicates, some of the factors are availability, affordability and large numbers of khat chewing canters are some to mention.

Table 2:-Chat Chewing Frequency and Starting Time

\begin{tabular}{|l|l|c|c|}
\hline \multirow{4}{*}{ How often do you chew chat per week } & Chewing Period/prevalence & Frequency & Percentage \\
\cline { 2 - 4 } & $1-2$ day & 14 & $5.3 \%$ \\
\cline { 2 - 4 } & $3-4$ day & 18 & $6.8 \%$ \\
\cline { 2 - 4 } & Every day & 232 & $87.9 \%$ \\
\hline \multirow{5}{*}{ When did you start chat chewing? } & Total & $\mathbf{2 6 4}$ & $\mathbf{1 0 0 \%}$ \\
\cline { 2 - 4 } & Starting at & 171 & \\
\cline { 2 - 4 } & Elementary School & 35 & $13.3 \%$ \\
\cline { 2 - 4 } & Secondary School & 21 & $7.9 \%$ \\
\cline { 2 - 4 } & Preparatory School & 37 & $14 \%$ \\
\cline { 2 - 4 } & University & $\mathbf{2 6 4}$ & $\mathbf{1 0 0 \%}$ \\
\cline { 2 - 3 } & \multicolumn{2}{|c}{ Total } & \\
\hline
\end{tabular}

\section{Perceived health effect}

Out of the total respondants, 250 (94.7\%) of the respondants said that chewing chat has its own significance negative effect on the health of chat chewers and its families, the economy of the region and the country in general and few of the respondent 14 (5.3) didn't know the negative impact of chewing chat. From this study the majority of the respondents perceived that khat chewing practice had significant harmful effect on health of chat chewers and the perceived health effect reported were slapping disorder, hallucination ,hypertension, loss of appetite, depression and gastrointestinal adverse effect like gastritis. 
One of the objectives of this study, as it is clearly indicated in the objective section, is to identify health consequence of abusing khat. Accordingly about $94.7 \%$ of current khat chewers reported that they were aware of the health effect of khat while only $5.3 \%$ of the respondent were not. Hence, knowledge of health consequence associated to khat chewing is not necessarily a protective factor against use of khat. Lack of sleep, losing appetite, physical wekness and depression were identified as the major health challenges associated to the respondent' khat intake. The impact of khat chewing on appetite was revealed by heymann et al (1995) which was similar to the finding of this study.

Table 3:-Perceived health effect

\begin{tabular}{|c|c|c|}
\hline Perceived health effect & Frequency & Percentage \\
\hline Yes & 250 & $94.7 \%$ \\
\hline No & 14 & $5.3 \%$ \\
\hline Total & 264 & $100 \%$ \\
\hline
\end{tabular}

\section{Initiators and reason to chewing khat}

Majority of the khat chewers initiated by Peer pressure (22.7\%) followed by Ceremony of khat (20.45\%), academic purpose $(18.93 \%)$ and family chewing habit $(15.2 \%)$. Few of the study participants continued khat chewing practice since then for religion purpose (12.5\%) and others like pleasure and recreation $(10.22 \%)$ as shown in table 4. From the data collected from the respondent, the majority of them were replied that the reasons for chewing chat were alertness (38.06\%), concentration (23.20\%); energy (21.22\%) and enjoyment (17.52\%) as shown in Figure 2.

The major reason claimed for initiation and continuation of khat chewing were peer pressure, academic purpose and stress reduction. This is an important indication to direct interventions towards decreasing the prevalence of this behavior since the major reasons were identified it is a problem half way solved. Different studies proved that gender and closely linked to lifestyle and the use of khat (Ihunwo et al 2004; WHO, 2010) .Gender wise, researchers have found that men are more likely to suffer from adverse health effect of khat chewing than women. Consistent to this study the current study revealed that there are statistically significant association between being males in their childhood and their later lives.

Table 4:-Initiators to chewing khat

\begin{tabular}{|c|c|c|c|}
\hline & Reason & Frequency & Percentage \\
\hline \multirow{7}{*}{ Initiators to chewing khat } & Peer pressure & 60 & $22.7 \%$ \\
\hline & Academic purpose & 50 & $18.93 \%$ \\
\hline & Ceremony ok khat & 54 & $20.45 \%$ \\
\hline & Religion purpose & 33 & $12.5 \%$ \\
\hline & Family chewing habit & 40 & $15.2 \%$ \\
\hline & other & 27 & $10.22 \%$ \\
\hline & Total & 264 & $100 \%$ \\
\hline
\end{tabular}




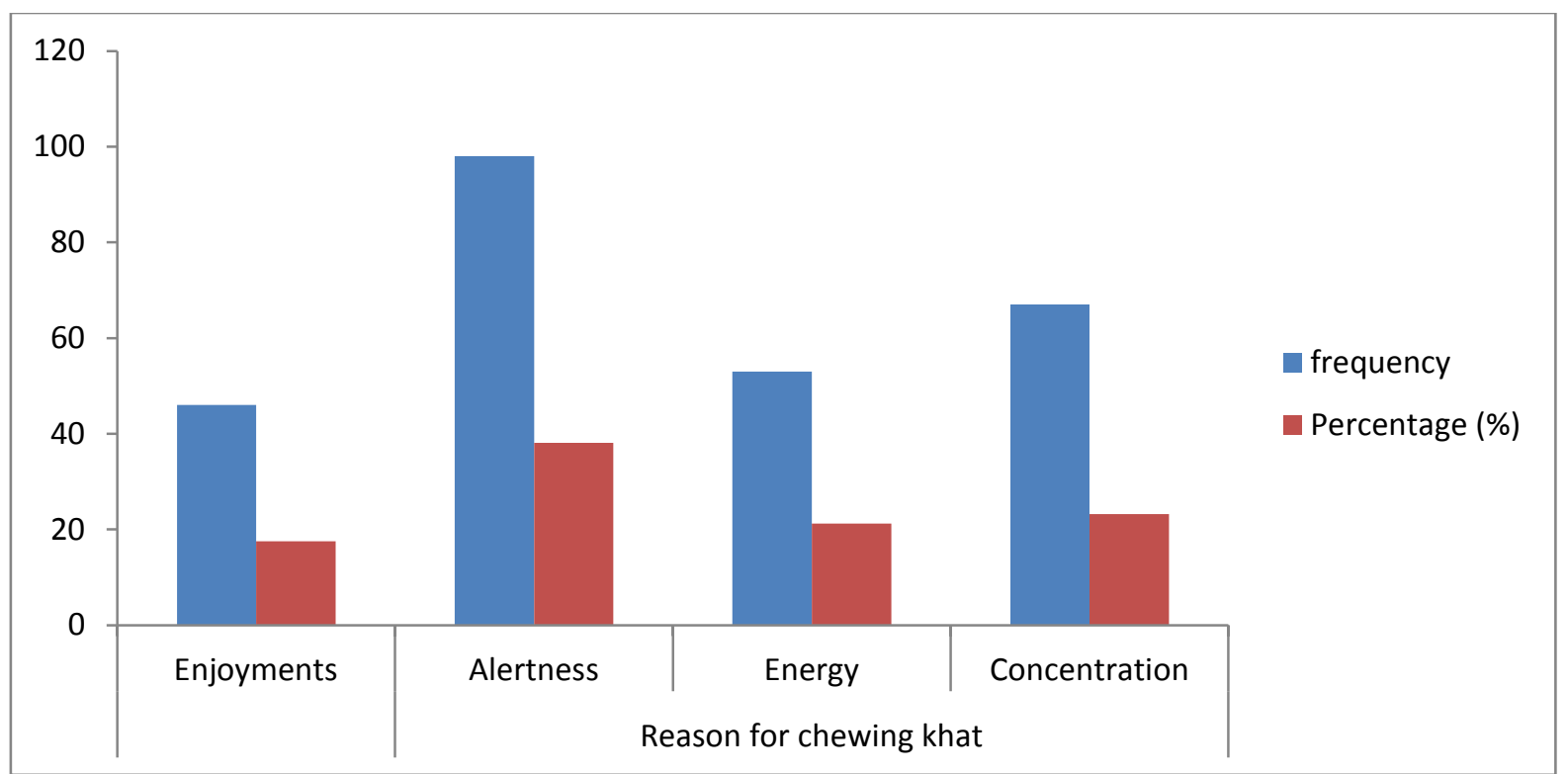

Figure 2:-Reason for chewing khat

Khat Chewing and health related Problems

Health effect of substance use was one of highly emphasized risks by many provirus studies. This research also considered the negative effect of khat abuse oh health although it appears difficult to exactly measure and evaluated the effect of khat chewing on health effort has made through listing out of incidence of health related problem as a result of khat chewing. Broader health problems have been classified in to two categories physical and mental illnesses of for ease of managing the data. Accordingly the finding shows 89 (33.7\%) respondent had reported problem of Sleepiness, while $64(24.1 \%)$ of respondents had the same for mental illness from simple to severe headache of the same period, 50 (18.9\%) Losses of Appetite and 35 (13.3\%) replied that lack of Concentration is due to chat chewing practice. Fourteen (5.5\%) of the respondants said that physical weakness as a result of khat chewing at least once in the last 12 month. On the other hand the researcher tried to find about $12(4.5 \%)$ of the respondent affianced in other activities like sexual practices which might be unsafe as shown in figure 3.

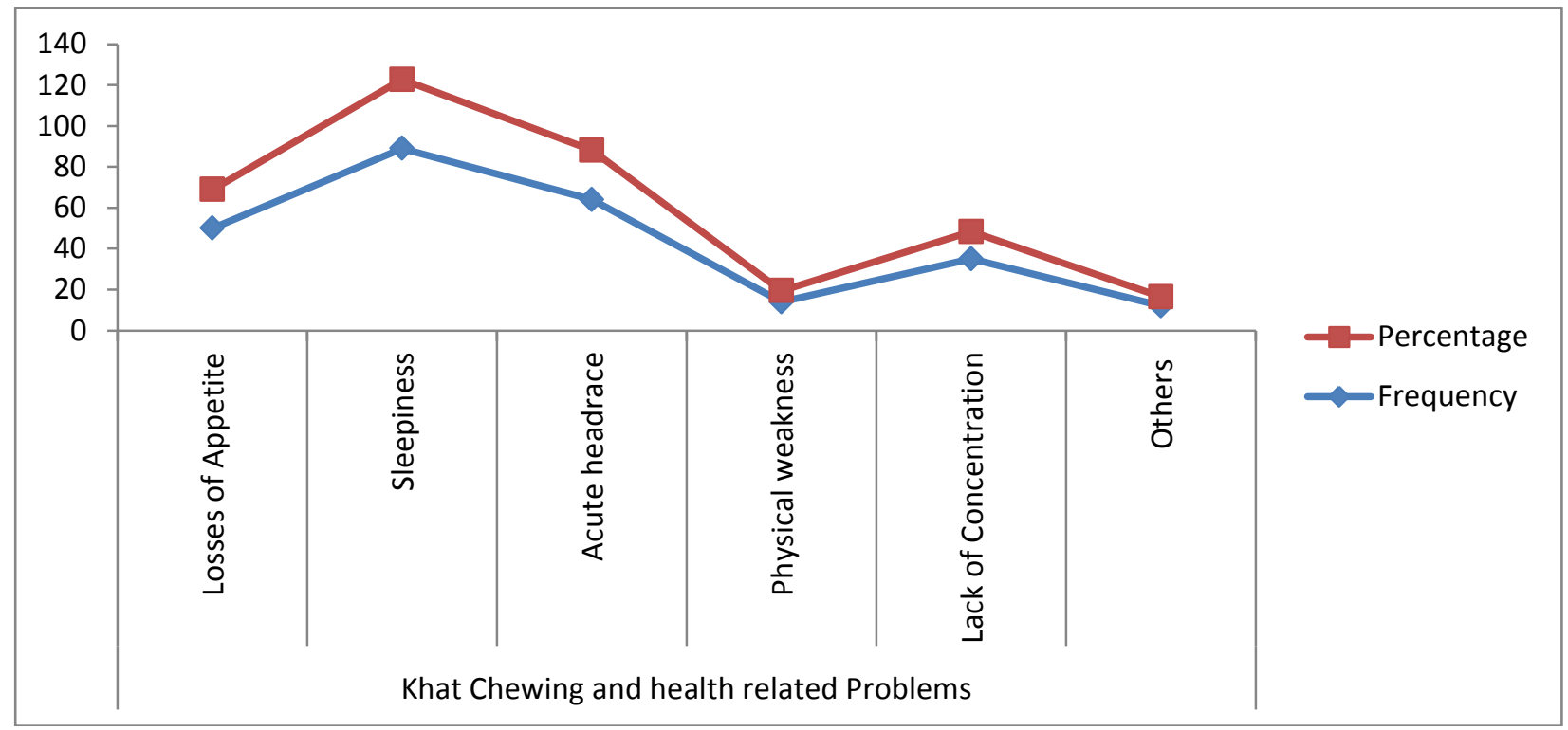

Figure 3:-Khat chewing and the prominent related problems among chiro community 


\section{Khat chewing and Associated Risks among Community}

In order to assess problems associated to khat chewing, as can be seen from table 5 below about 68 (25.8\%) engaged in other drug( e.g tobacco and alcohol); 54 (20.5\%) reported sleeplessness and night mare;47 (17.8\%) were reported headache to simple depression after khat chewing ;42 (15.9\%) reported loss of appetite ; 34 (12.9\%) replied physical weakness or deterioration and $19(7.1 \%)$ engaged in sexual intercourse that regrets themselves in the next day. The chained effect of khat didn't end even here rather it goes to the extent of affecting the sexual life of respondent as it initates the intake of other substances such as alcohol and tobacco which most of the time is followed by Sleeplessness and night mare, Headache to simple depression after chewing, Losses of appetite, Physical weakness and deterioration and engaging in risky sexual practices. Consistently the study by Dawit et al.,( 2005), highlighted that khat chewer to abuse tranquilizers and to indulge in alcohol as a means of overcoming the side effects and leads to tension on family relations trough increased sexual arousal and most likely multiple sexual intercourse.

Table 5:-Khat chewing and Associated Risks among Community

\begin{tabular}{|l|l|l|l|}
\hline & & Frequency & Percentage \\
\hline \multirow{4}{*}{$\begin{array}{c}\text { Associated Risks } \\
\text { among Community }\end{array}$} & Engaged in other drug & 68 & $25.8 \%$ \\
\cline { 2 - 4 } & Sleeplessness and night mare & 54 & $20.5 \%$ \\
\cline { 2 - 4 } & Headache to simple depression after chewing & 47 & $17.8 \%$ \\
\cline { 2 - 4 } & Losses of appetite & 42 & $15.9 \%$ \\
\cline { 2 - 4 } & Physical weakness and deterioration & 34 & $12.9 \%$ \\
\cline { 2 - 4 } & Engaged in sexual intercourse & 19 & $7.1 \%$ \\
\cline { 2 - 4 } & Total & $\mathbf{2 6 4}$ & $\mathbf{1 0 0 \%}$ \\
\hline
\end{tabular}

\section{Khat Chewing and Psychological Problems}

Accordingly out of the 264 respondants as shown in table 6 below, the majority of the respondants (26.52\%) replied that chat chewing practices causes sleeplessness and lack constant concentration or mood disturbance; $22.7 \%$ Reduce appetite; $19.7 \%$ depression and $14.4 \%$ of the respondents experienced gastrointestinal adverse effect. Few of the respondants; $12.12 \%$ said that hallucination and $4.54 \%$ of the respondants experienced hypertension psychological problems on chat chewers.

Table 6:-Perceived effect of khat chewing

\begin{tabular}{|l|l|c|c|}
\hline & Perceived effect of khat chewing & Frequency & Percentage \\
\hline \multirow{4}{*}{ In detail negative health effect } & $\begin{array}{l}\text { Sleeplessness and lack constant } \\
\text { concentration or mood disturbance }\end{array}$ & 70 & $26.52 \%$ \\
\cline { 2 - 4 } & Reduced appetite & 60 & $22.72 \%$ \\
\cline { 2 - 4 } & Depression & 52 & $19.7 \%$ \\
\cline { 2 - 4 } & Gastrointestinal adverse effect & 38 & $14.4 \%$ \\
\cline { 2 - 4 } & Hallucination & 32 & $12.12 \%$ \\
\cline { 2 - 4 } & Hypertension & 264 & $4.54 \%$ \\
\cline { 2 - 4 } & \multicolumn{1}{|c|}{ Total } & $100 \%$ \\
\hline
\end{tabular}

\section{Conclusion:-}

The prevalence of chewing practice was $62 \%$ with high proportion of the khat chewers found in the urban setting, sex, religion, residence, family chewing habit and perceived health effect were significantly associated factors with khat chewing practice and peer pressure was found to be the major reason that initiated individuals to begin khat chewing practice. In this study $94.7 \%$ of the respondent perceived that khat chewing practice had harmful effects on health effects on health and the perceived health effects reported were sleeping disorder, hallucination, loss of appetite, depression, gastritis and hypertension.

\section{Recommendation:-}

To sum up using this as a preliminary study, further investigation should be continued to explain exhaustively the effect of chronic khat chewing on the mental health and detailed experimental work on the cardiovascular effect of khat. Khat chewing is also suspected to be the risk factor of peptic ulcer disease. This again needs careful observation. Health education about the adverse effect of khat chewing should be delivered to the community and 
health institutions. Based on this recommendation, policy makers should design strategies to control the production, usage distribution of Khat in Ethiopia particularly in West Hararge Zone, Oromia Regional State.

\section{Acknowledgements:-}

I would like to extend my sincere appreciation to Oda Bultum University College of Natural and Computational Science, Department of Biology and Research and Community Engagement Office for financial support. Without their invaluable support this paper wouldn't have materialized. I would like to express my heartfelt thanks to the staff and participant who live in the town for the assistances and generously complete the self administered questionnaire used for the research.

\section{Reference:-}

1. Adugna, jira C, Molla T (1994). Khat chewing among Agaro secondary student, Agaro,South western Ethiop Med J 32(3); 161-6.

2. Ageely H.M (2009)' prevalence of khat chewing in college and secondary school students in sthe jaza ergion,Saudi Arabia ,harm reduction journal VOL .6 NO.11 Accessed online on 20/07/2010. DOI:

3. Agresti A.(2007) An Introduction to categorical data analysis ( $2^{\text {nd }}$ edition) Department of statically university of florida Gainesville florida wily enterprise A john wiley and sons inc.puplication .

4. Ahmed A, Kathryn B and Krnnethf (2002) khat. Pharmacological and medical aspect and its social use Yemen review article.

5. Ahmed Elkashef. Abdullah Al sharqi and Rashad Al.sanausy (2013) pharmacological treatment of khat and other stimulants use disorder.

6. Alem A. kebede D. Kullgren (1999) the prevalence and demographic correlates of khat chewing in butajira, Ethiopia. Acta psychiatry scand suppl 397 (84-91)

7. Belew M, Kebede D and Kassaye M. Khat use and its associated health and socio-economic effects in a general population. Ethiopian Medical journal 2000; 38:11-26

8. Cox G and Rampus H (2003) adverse effect of chewing review journal of counting professional development Advance in psychiatric treatment VOL .9 456-463

9. Creswell.J.W. (2003) Resarch Design Qualitative, Quantitative and mixed Methods Approches. London: sage. $2^{\text {nd }}$ Ed.

10. Dawit A, Asfaw D, Amare D, Ambaye D, Almaz A, Kelbessa U, et al. (2005). Khat chewing habit as possible risk behavior for HIV infections; A case- control study, Ethiop,j, Health Dev19(3);1(74-181)

11. Dalu A.(2008). The impact of long term consumption of khat on public health. Accessed on line on 27/07/2010 http/WWW.The sidam concern.com /articles/abrham.htm/.

12. Ihunwo,A,O.,Kayanja,F,L,B.,Amadi-Ihunwo,U,B,(2004).Use and percepitation of the psycostimulant,Khat( Catha edulis) among three occupational group in south western Uganda,East African Medical Journal 8(9).

13. Kalix p (1994) khat on amphetamine like stimulant journal of psychoactive Drugs 26.pp.69-74.

14. Mbalu,M.,(2012).Factors Infiuencing Prevalence of drug use among secondary school student in kitui central District, Kenya.

15. Melkamu Y.(2007). Identifying At Risk populations and HIV/AIDS Referral services : Baseline Assessment for Mobile Counseling and Testing Program in the Amhara Region of Ethiopia, Bethesda,MD; Private sector Program(PSP)-Ethiopia project, Abt Associates Inc, November 2007.

16. World Health Organization (2006); Regional workshop on preventation, management and Treatment of Alcohol and proactive substance use Disorders in the African Region, Brazzaville: World Health Organization Regional Office for Africa.

17. Yousef G, Hug Z, Lambert T. Khat chewing as a cause of psychosis, Br J Hosp Med (1995); 54(7): 322-26 